\title{
Quantitative analysis on the fluctuation of vegetable price in supermarket
}

\author{
Suci Miranda* and Vembri Noor Helia \\ Industrial Engineering Department, Faculty of Industrial Technology, Universitas Islam Indonesia, Indonesia
}

\begin{abstract}
In this paper we analyze the variables affecting the determination of vegetable sale price in supermarket and investigate each amount considered into the formulation. We use the supermarket pricing strategies literatures, cost management theory, and any information obtained from suppliers and supermarket to investigate the variables influenced the sale price gap between supplier sale price and supermarket sale price. In order to obtain the supermarket sale price, it is required to understand the concept of costs. Supermarket as a merchandising firm has two components of costs called purchase costs and operating expenses which are computed to be Cost of Goods Sold (COGS). We found that supplier sale price is the purchase costs and plays has the main role in determining the supermarket sale price. The operating expenses considered is the holding cost. The vegetable characteristics and consumer behaviour have driven the contribution of amount of variables into the sale price at supermarket. Finally, we present the variables satisfying the vegetable sale price formulation and how they are calculated becoming the supermarket sale price.
\end{abstract}

\section{Introduction}

Vegetable has a great economic value for agribusiness sector. As one of consumers' needs, they are not only sold in traditional markets, but also in modern markets such as supermarkets. In fact, most supermarkets have offered similar quality of Fresh Food and Vegetable (FFV) to wetmarkets but at higher prices on avegare 15\%-60\% above traditional retailers [4]. Competition in the supermarket industry is a complex phenomenon in which firms have to compete across the entire retail and marketing mix, enticing customers with an attractive set of products, competitive prices, convenient locations, and a host of other services, features, and promotional activities [3]. Firms choose a set of services and features that maximize profits, conditional on the types of consumers they expect to serve and their beliefs about the actions of their rivals.

A supermarket's pricing strategy is a main element in order to achieve its profit. Choosing a strategy is quite elaborate that managers must balance the preference of their consumers and their firm's own capabilities againts the expected actions of their rivals [7]. While according to data in Central American, the supermarket share in FFV retail is most four times smaller that in overall retail [4]. The clear advantage of supermarkets over traditional markets are convenience, safety, and cleanliness. Supermarkets must maintain consumer loyalty as well as to maximize profit.

From different point of view, some studies have been conducted on fluctuation in the prices of vegetables and also the supermarket pricing strategies. A detailed description of supply chain of vegetables has revealed the reason for great fluctuation in the prices in China and gives the recommendations for stabilizing the prices of vegetables [8]. A prediction of vegetable sale price has been established using a Markov Chain model in order to solve the problems of heavy price fluctuations and unbalanced reources allocation in the vegetable wholesale market caused by large daily demand and varied supply channels in China [10]. [7] observed the supermarket pricing strategy using a system of simultaneous dicrete choice models on the underlying features of the market, as well as each firm's beliefs regarding its rival's actions. [3] studied the inventory management decisions of retailer selling a single perishable good in a deterministics settings, formulate and analyze an EOQ model with demand decreasing in the age of the product for both fresh produce and packaged goods. [6] addressed the impact of consumer purchasing behaviour on the production planning of perishable food products for companies operating in the fast moving consumer good using direct store delivery. [5] modelled an EOQ for the inventory management of perishables in small medium-sized grocery stores using a regression approach from the product's holding, lifetime, and markdown policy. It recorded that managers frequently utilize markdown to stabilize demand when the products expiration date nears. While in this sale price analysis study, the markdown policy is not applied in supermarket observed. Yet, the lifetime will be considered as one of the variables influencing the sale price determination. It is along with another research that formulates and analyzes an EOQ

* Corresponding author: suci,miranda@uii.ac.id 
model with demand decreasing in the age of the product [7].

Yogyakarta is one of special province (DIY) and is the second largest tourist destination in Indonesia with a small expatriate community living here reached 2,500 by the end of 2015 (Immigration, Yogyakarta). Due to the vegetable supply and demand, this has given a new opportunity in agribusiness providing vegetables for residents by establishing green groceries where are close to housing. These stores provides FFV with convenient places and cleanliness even though they are smaller than supermarkets. Competing with supermarkets and traditional markets, the green groceries need a pricing strategy in order to determine a sale price of vegetables. The main business purpose is to gain profit while these groceries are lacking of adequate information how to formulate the sale price [9]. Despite the supermarket pricing strategy, there has not been a representational framework of determining the vegetable sale price for a green grocery. Building on the supermarket pricing strategies literatures, production cost theory, and information obtained from suppliers, we analyze the major factors that drive vegetable pricing formulation in supermarkets particularly in Yogyakarta, and how much each factor contributes into the sale price formulation. We use a supply chain for investigating the sale price gap of every chain and the factors influenced, and cost plus pricing analysis considering the direct and indirect cost for the sale price formulation. Finally, we present the result of the variables and each percentage counted into the formulation.

The rest of the paper is organized as follows. Section 2 explains the reasons of the fluctuation in vegetable sale price in Indonesia. Section 3 describes the analysis of vegetable pricing method in determining the sale price at supermarket. Section 4 concludes and identifies opportunities for future research.

\section{Analysis of Fluctuation in the Price}

The objects of research are non-organic vegetable which have a great price fluctuation: red onion, garlic, red chilli pepper, big red pepper, and cayenne pepper. The highvalueable vegetables such as peppers, onions, and tomatoes are different with other vegetables such as kale, spinach, and green mustard. As the basic ingredients in most of Indonesian recipes such as rendang and curry, the supply and demand play a main role on the fluctuation. There are $93.1 \%$ and $80.7 \%$ of 462 respondents who consume onion and red pepper almost every day [1]. Total supply in the market will affect suppliers to meet demand from supermarkets particularly when the price of chili, onions, and tomatoes fluctuate sharply, it will influence the price offered by the supplier to supermarkets, then the higher sale price continues from supermarkets to the end consumer. These are the following reasons driving the fluctuation in Indonesia. First. The safety stock mechanism has triggered the increase if the supply are not sufficient for the demand. For instance, due to a shortage supply of onions, the rest onions will be imported for stabilizing the price. Meanwhile, the local onions are sold at a higher price instead. This condition can be caused by the high production costs applied (Bappenas, 2013). Second. Indonesia has 2 seasons, rainy season and dry season. Onions and pepper can not grow well during the rainy season which the production will decrease significantly. It is obvious that the price will be more expensive because the supply is lower than the demand. Third. The supply chain of vegetables. The vegetable industry is an industry with a strong concept of supply chain. The supply chain nodes can be analyzed one by one to subdivide the prices of vegetables into all nodes of supply chain of vegetables if the supply chain can be potrayed in detail in order to conduct effective analysis of great fluctuation in the prices [8].

This paper selects the main data on the prices of vegetables from a national supermarket with 8 branches in Yogyakarta and a main supplier of this supermarket. The sale price within 6 months observation are shown in Figure 1.

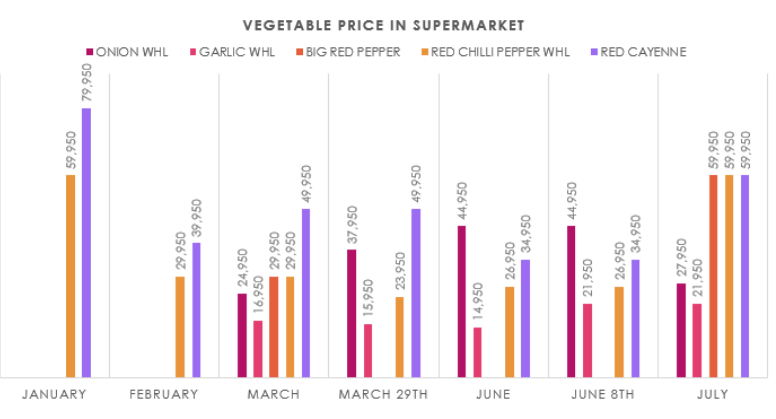

Fig 1. The fluctuation price of vegetables in supermarket (Rp) Source: Data compiled from supplier and supermarket

As can be seen from Table 1, the sale price has risen almost every month especially for red cayenne and onions. Indonesia has lots of spicy food, so red cayenne and red chilli pepper are preferred into the main course, not only for home cooking, but also at restaurant like Padang restaurant. While garlic does not increace sharply because it is used little than onions in every recipe. Sambal or pepper sauce comprises 8 onions and 2 or 3 garlics, for example. Compared to the sale price from supplier to supermarket shown in Table 1, there is a gap sale price $(\Delta p)$ that will be identified in further section.

Table 1. Supplier and supermarket sale price

\begin{tabular}{lccc}
\hline Item & $\begin{array}{c}\text { Supplier } \\
(\mathrm{Rp})\end{array}$ & $\begin{array}{c}\text { Supermarket } \\
(\mathrm{Rp})\end{array}$ & $\begin{array}{c}\Delta p \\
(\mathrm{Rp})\end{array}$ \\
\hline Garlic WHL & 15,500 & 16,950 & 1,450 \\
Onion WHL & 34,000 & 37,950 & 3,950 \\
Big red pepper & & & \\
WHL & 20,000 & 23,950 & 3,950 \\
Red chilli pepper & & & \\
WHL & 30,000 & 49,950 & 19,950 \\
Red cayenne WHL & 14,500 & 29,950 & 15,450 \\
\hline
\end{tabular}

Source: Data compiled from supplier and supermarket

Table 1 shows the different sale price from supplier to supermarket and from supermarket to end consumer displayed at the shelves. The highest gap is red chilli 
pepper reaching up to Rp. 20,000 followed by red cayenne with Rp. 15,450 gap price which is $100 \%$ higher from the supplier sale price. This fluctuation price of vegetables is frequent in Indonesia, so we must face the abnormal price phenomenon.

\section{Analysis of Vegetable Pricing Method}

These vegetables observed are part of non-leafy vegetables with the aging group (a) is a +1 (they can last for more than one day) and their shelf life ( $t)$ is $t+1$ [9]. The non-leafy vegetables means the leaves are not consumed as the main course but their root or stalk. They will be placed at the shelf for more than one day $(t+1)$ as their freshness can last more than one day $(a+1)$ started from the day they are purchased. All of them are sold in kilogram without packaging and have a random lifetime (there is no expired date).

The supermarket is supported by more than 15 suppliers for FFV that every supplier has to follow the supermarket policy related to the vegetables demanded such as the packaging, the weight, barcode, and the size. When the vegetables are purchased a day before to each supplier, they are ready to be put into the shelves once they arrive at supermarket next morning, as the supply chain can be seen in Figure 2. Supermarket provides checkers as a quality controller of vegetable supply. The responsbilities of a checker are to check all vegetable from suppliers every morning, and to ensure the number and the physical condition of vegetables in order to meet the quality standards of supermarket. The checker also has to check the freshness and neatness of vegetables at their shelves regularly.

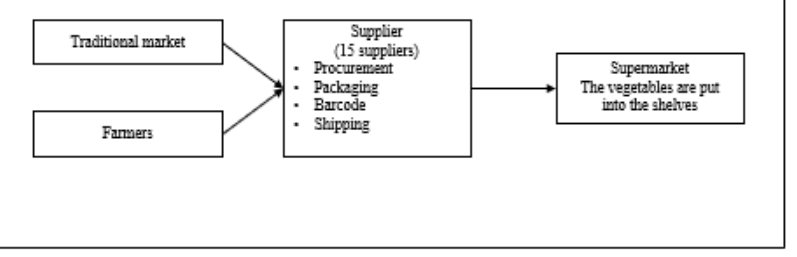

Fig. 2 Vegetable supply chain

Before calculating the sale price of vegetable called the cost of goods sold (COGS), we need to define what kind of firm it is. There are three kinds of firms: manufacturing, merchandising, and service firm. Since supermarket does not manufacture inventory of vegetables, hence it is a merchandising firm who purchases inventory. It means that merchandising firm sells products but not make them. According to [2], the process is a merchandising firm is simpler than manufacturing firm which is purchases merhcandise and places it in the product inventory account. Once it is sold, it is transferred to the cost of goods sold (COGS) account.

All other costs for managing the firm and selling the product are not product costs such as advertising costs, data processing costs, facilities costs, and executive and staff salaries. The non product costs are called period costs. In merchandising firm, period costs are also sometimes referred to operating expenses or selling and administrative expenses. It has been explained before that these vegetables have the aging group (a) stated a +1 (they can last for more than one day) and their shelf life ( $t$ ) defined $t+1$. They are purchased every day to suppliers, even though some of them are left in the shelves. Due to the stock on the shelf $(t+1)$ treated as inventory, so holding cost is considered as an operating expenses. The other operating expenses such as marketing cost, and general and administration such as the checker salary must be included in the calculation of the COGS. Unfortunately, we only know quite a bit of the information needed due to the confidential issues. The COGS formula is a way of determining the costs attributable to the products sold, after determinig how much of the inventory stocks are still on hand. The cost of goods sold (COGS) will be calculated as follows:

Where:

$$
\mathrm{BI}+\text { Purchase }-\mathrm{EI}=\mathrm{COGS}
$$

$$
\begin{array}{ll}
\text { BI } & =\text { Beginning inventory } \\
\text { EI } & =\text { Ending inventory } \\
\text { COGS } & =\text { Cost of goods sold }
\end{array}
$$

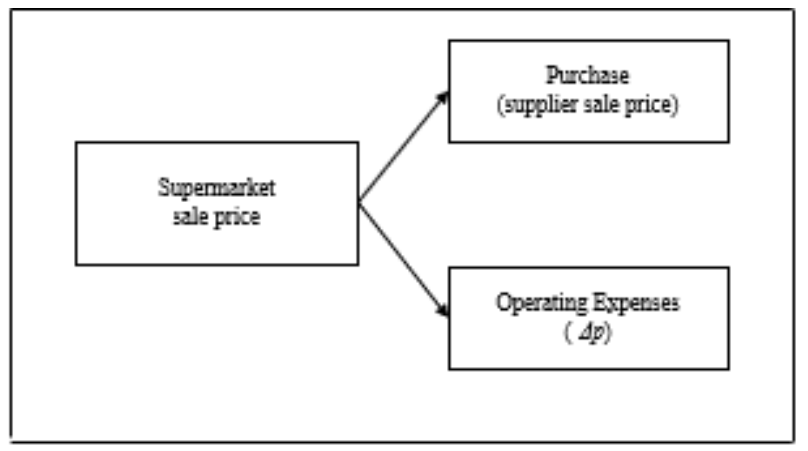

Fig. 3 Conceptual nodel

Figure 3 explains the steps of computing supermarket sale price. According to the equation (1) above, purchase costs of vegetables is directly gained from the supplier sale price to supermarket. The price gap $(\Delta p)$ called operating expenses will be broken down into variables considered and the amount of each. This cost will clearly be explained in Table 2 below.

The holding cost for perishable products ranges between $15 \%$ to $35 \%$ [3]. It is set fixed in every period $t+$ 1 for each vegetable on the shelf [9]. For the holding cost of garlic, onion, and red chilli pepper, they are between $3 \%-5 \%$ which is lower than the recommended holding cost around $15 \%-35 \%$ [5]. While cayenne pepper and big red pepper are higher at $35 \%$ [3]. The difference treatment can be caused by the characteristics of red chili pepper, onion, and garlic which play a central role in Indonesian cuisine. Cayenne pepper is the most spicy among the peppers. Having a small bite of cayenne pepper will give a stronger taste instead. Meanwhile, the red chilli pepper is more spicy than the big red pepper. For red chilli pepper, it can be cooked to stir with thinly sliced so it feels more spicy. As for big red pepper is more often used to make a smoothed cooking spice. It can be concluded that red chilli pepper is consumed regularly compared to 
cayenne pepper and big red pepper. With a different number of demand, the supply of onion, garlic, and red chilli pepper into the shelf will be more frequent.
Therefore, the red chilli pepper and big red pepper require a greater holding cost. The processing results are shown in Table 2.

Table 2. The cost of goods sold of vegetables in supermarket

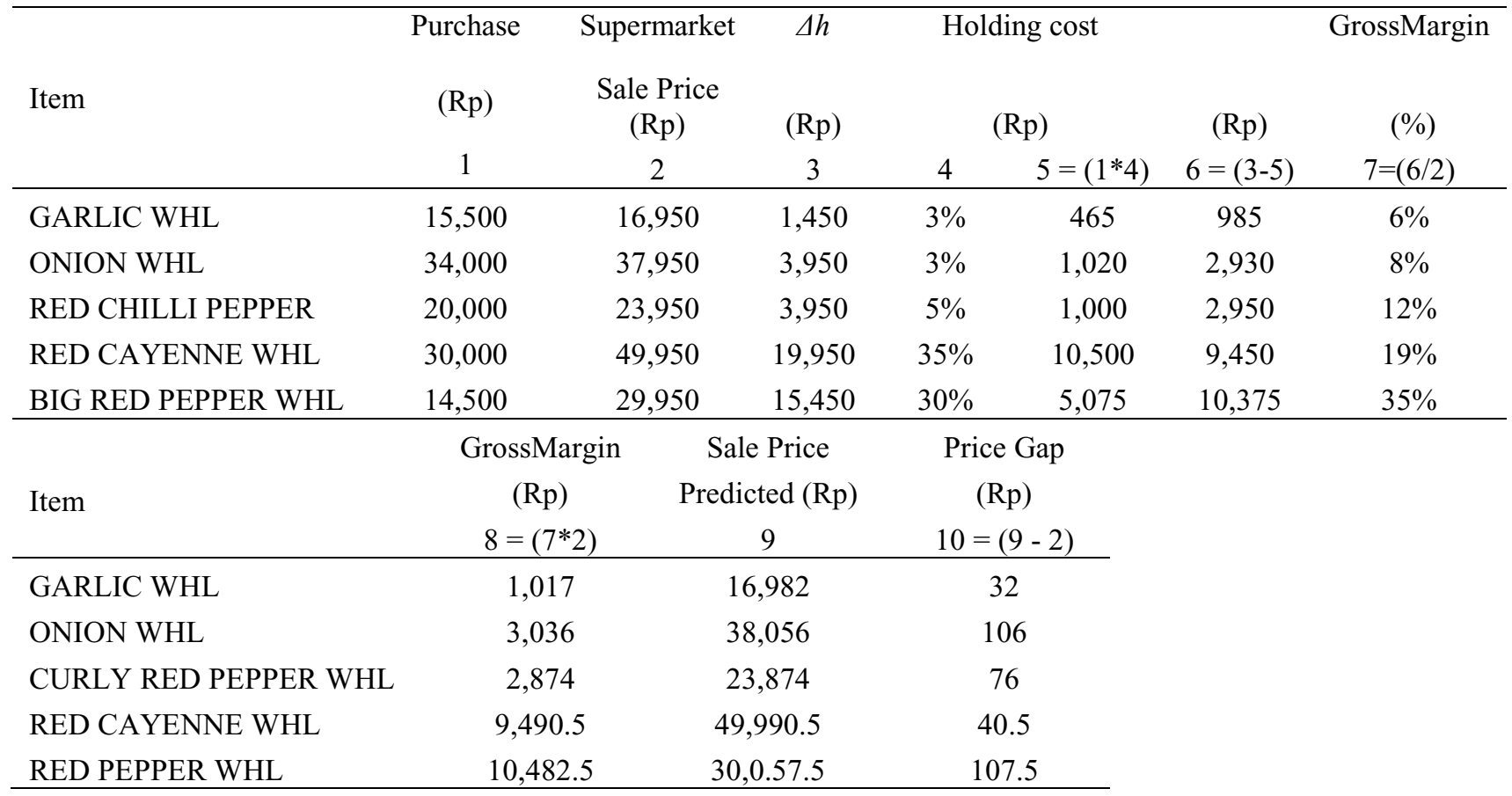

The contribution margin rate (CMR) is suggested at $10 \%$ for retailers [5], but based on the calculation, each item is applied different margin rate. Red pepper is the highest margin rate which is equal to $35 \%$ of the total revenue. It may be caused by the utility of it in the main course recipes. Consumers prefer red cayenne and red chilli pepper that are more spicy than the big red pepper, thus it also affect its demand as well as the sales at supermarket. The margin can be set higher in order to gain a higher profit, so the sale price to the end consumer will be more expensive than the supplier sale price to supermarket. In calculating the merchandising firm gross margin, it is needed the sale data substract the cost of goods sold. However, the sales data can not be obtained from supermarket, so it is defined by using coloumn 6 divide by coloumn 2 in Table 3 . As can be seen in Table 3, when the gap sale price between supplier and supermarket higher, the gross margin increases. For example, garlic's gap sale price is Rp. 1,450 or $9 \%$ higher than the supplier sale price, and gross margin is $6 \%$. Whereas big red pepper is $\mathrm{Rp}$. 15.450 or it is around $100 \%$ more expensive than the supplier sale price with gross margin of $35 \%$.

Using this traditional pricing approach in merchandising firm, the predicted sale price is close to the actual sale price at supermarket showed in coloumn 9 in Table 3 above. Finally, the supermarket sale price consist of purchase cost, the holding cost, and gross margin.

\section{Conclusions and Directions for Future Research}

These vegetables have a lifespan of more than a day $(\mathrm{a}+$ 1) and the shelf life $(t+1)$ with the random life (expiration date is not listed), and sold in kilogram. Since all vegetables are supplied by suppliers, so the supplier sale price to supermarket is treated as the purchase cost. It plays an important role in the formulatin of sale price at supermarket. The price gap $(\Delta h)$ or operating expenses between supplier and supermarket sale price comprises selling expenses and administrative expenses. Price is a confidential issue so some informations of Beginning inventory, Ending inventory, sales, and other operating expenses are assumed 0 . There is only one operating cost which can be identified, the holding cost, while the others expenses are set 0 . For further research, the data needed could be obtained from more than one supplier and supermarket so it will provide a robust data for analyzing the variables. The sale price of vegetables from green groceries may also be added in order to gain the gap sale price between supermarkets and the green groceries. The qualitative analysis is important in identifying a characteristic of vegetables which may be considered in determining the sale price as well as the consumer behaviour in purchasing these vegetables. Finally, by gaining adequate informations related to factors influencing the determination of vegetable sale price both quantitatively and qualitatively, a better guide line 
of business growth can be provided for those green groceries.

\section{References}

1. A. Witono (2011). Faktor-faktor yang mempengaruhi perilaku dan keputusan konsumen untuk membeli kentang, bawang merah, dan cabai merah. J.Hort. 21, 3 (2011)

2. E. J. Blocher, D. E. Stout, and G. Cokins, Cost Management, fifth edition, McGraw-Hill Irwin (2010)

3. G. Dobson, E. J. Pinker, and O. Yildiz O, An EOQ model for perishable goods with age-dependent demand rate, Eur. J. of Operation Research., 1-5 (2016)

4. J. A. Berdeguè, J. A., F. Balsevich, L. Flores, and T. Reardon, Central American Supermarkets' Private Standartd of Quality and Safety in Procurement of Fresh Fruits and Vegetables. Food Policy, 30, 254269 (2005)

5. M. Ferguson, V. Jayaraman, and G. C. Souza, Note: an application of the EOQ model with nonlinear holding cost to inventory management of perishables. Eur J. of Operation Research, 18, 485490 (2007)
6. P. Amorim, A. M. Costa, and B. Almada-Lobo, Influence of Consumer Purchasing Behavior on The Production Planning of Perishable Food, OR Spectrum, (2013)

7. P. B. Ellickson, and S. Misra, Supermarket Pricing Strategies, Marketing Sciences, 27(5), 811-828 (2008)

8. S. Chen, and L. Hu, Why Are There Great fluctuations in the Prices of Vegetables?, Asian Agri. Research, 5(3), 1-6 (2013)

9. S. Miranda., (2017). A Qualitative and Quantitative Analysis of Vegetable Pricing in Supermarket. Retrieved from http://www.researchgate.net/(2017)

10. X. Zhu and X. Xu, Markov Chain Analysis and Prediction on The Fluctuation Cycle of Vegetable Price, J. of Syst and Mngmnt Sciences, 2(3), 40-49 (2012) 